www.jmscr.igmpublication.org

Impact Factor (SJIF): 6.379

Index Copernicus Value: 79.54

ISSN (e)-2347-176x ISSN (p) 2455-0450

crossrefDOI: https://dx.doi.org/10.18535/jmscr/v6i9.186

Journal Of Medical Science And Clinical Research

IGM Publication

An Official Publication of IGM Publication

\title{
Clinical Profile and Outcome of Patients Admitted to Pediatric Intensive Care Unit of a Tertiary Care Teaching Hospital in Eastern India
}

\author{
Authors \\ Sarbani Misra $\operatorname{Roy}^{1 *}$, Suprit Basu ${ }^{2}$, Bidhan Ch $\operatorname{Roy}^{3}$, Supratim Datta $^{4}$ \\ ${ }^{1}$ Assistant Professor, Department of Pediatrics, Institute of Post Graduate Medical Education and Research \\ and SSKM Hospital, Kolkata, West Bengal, India \\ ${ }^{2}$ Senior Resident, Department of Pediatrics, Institute of Post Graduate Medical Education and Research and \\ SSKM Hospital, Kolkata, West Bengal, India \\ ${ }^{3}$ Assistant Professor, Department of Pediatrics, Institute of Post Graduate Medical Education and Research \\ and SSKM Hospital, Kolkata, West Bengal, India \\ ${ }^{4}$ Professor and Head, Department of Pediatrics, Institute of Post Graduate Medical Education and Research \\ and SSKM Hospital, Kolkata, West Bengal, India \\ *Corresponding Author \\ Sarbani Misra Roy \\ 369, Purbachal Kalitala Main Road, Kolkata, West Bengal, India, Pin 700078 \\ Email: misra.sarbani@gmail.com, Contact No 9434305619
}

\begin{abstract}
Introduction: Pediatric intensive care has become very important in the management of critically ill children who need advanced airway, respiratory and hemodynamic support with the aim to achieve better outcome.

Materials and Methods: A retrospective study was done in children aged more than 28 days to 12 years admitted to a pediatric intensive care unit (PICU) of a tertiary care teaching hospital in Eastern India. over a period of one year - from $1^{\text {st }}$ January 2017 to $31^{\text {st }}$ December 2017.The records of all admissions were reviewed. The results are tabulated in Microsoft excel.

Results: Of the 481 children admitted, 360 patients (74.34\%) survived. 309 (64.24\%) were male and 172 $(35.76 \%)$ were females. Maximum number $(n=170,35.34 \%)$ of cases admitted belonged to the age group > 28 days to 12 months and maximum death $(n=51,43.59 \%)$ also occurred in this age group. Under five mortality was 83 (64.51\%) (including 43.59\% infant mortality and excluding neonates). Of the 136 (37.78\%) patients required mechanical ventilation, $63(46.32 \%)$ patients were successfully recovered. Three most common disease categories required admission were central nervous system $(n=128,26.61 \%)$ respiratory $(n=112,23.28 \%)$ and gastrointestinal $(n=63,13.1 \%)$.
\end{abstract}

Conclusion: More studies are required to assess the overall outcomes of critically ill children in India. Epidemiologic analysis of these patients can aid in redistributing the resources and improve the outcome.

Keywords: critical illness, epidemiology, pediatric intensive care unit, outcome.

\section{Introduction}

Since the first intensive care units (ICUs) were established in the United States in the 1960s, intensive care gradually has become very important in the management of critically ill patients. Paediatric patients who are critically ill and need advanced airway, respiratory and 
hemodynamic support are admitted in Pediatric intensive care unit (PICU) to improve outcome. Intensive care is offered to the patients whose condition is potentially reversible and have a good chance of survival with intensive care support. The objective of pediatric critical care is to decrease the mortality and to restore the child, who is suffering from a life- threatening condition, to health with a minimum pain, anxiety and complications $^{(1)}$ This, however, comes at a huge cost to all the parties involved, the hospital, the personnel, and the care givers of patients. The outcome of these patients can evaluate and assess the efficacy of treatment, making it possible to take better decisions to ensure the effective management of the high-level resources and optimize the resource utilization. This study is, therefore, conducted to audit the pattern of cases being admitted to our PICU and their outcome. The term "audit" here implies a professional commitment to improvement and involves a systematic approach highlighting the opportunities for improvement and positive change in clinical practice $^{(2)}$.

\section{Materials and Methods}

This study was a retrospective record based study conducted in patients admitted to a pediatric intensive care unit (PICU) of a teaching hospital in Kolkata, West Bengal, in the eastern part of India, over a period of one year - from $1^{\text {st }}$ January 2017 to $31^{\text {st }}$ December 2017.Approval from the institutional ethical committee was taken. This hospital is a tertiary care, super speciality referral hospital. The well-equipped 8-bedded PICU caters to the needs of critical care of the in-patients from Pediatric Medicine and as well as from other departments like, Pediatric Surgery, Otorhinolaryngology, Neurosurgery, Orthopedics of this hospital. The records of all the admitted patients with PICU admission age criteria of $>28$ days to 12 years were reviewed and analysed. Details on age, sex, diagnosis spectrum, outcome, retrieved from the medical records and admission registers, and tabulated and analyzed using Microsoft Excel
(Microsoft Office2016). Outcome was classified as survived, left against medical advice (LAMA) and death.

\section{Results}

A total of 481 patients were admitted into PICU from January 2017 to December 2017. Of them, $309(64.24 \%)$ were male and $172(35.76 \%)$ were females. Male to female ratio was 1.8:1.

Table 1 shows the age distribution of the admitted children and fate. Maximum $(n=170,35.34 \%)$ number of admitted cases belonged to the age group $>28$ days to 12 months This was followed by the age group 13-59 months $(n=153,31.81 \%)$. age group 60-120 months $(\mathrm{n}=118,24.53 \%)$, and $>120$ months $(n=40,8.32 \%)$ in decreasing order. Under 5 year aged children constituted $(n=323)$ $67.15 \%$ ) cases. Table 2 describes the system wise causes of admission to the PICU and their relationship with the outcome. Three most common disease categories admitted were central nervous system $(\mathrm{n}=128,26.61 \%)$ respiratory $(\mathrm{n}=112,23.28 \%)$ and gastrointestinal $(\mathrm{n}=63$, $13.1 \%$ ) in this study. Other common causes of admissions were renal $(\mathrm{n}=59,12.27 \%)$, cardiovascular $\quad(\mathrm{n}=46,9.56 \%), \quad$ sepsis $(\mathrm{n}=39,8.11 \%)$, hematological $(\mathrm{n}=14,2.91 \%)$, miscellaneous $(\mathrm{n}=13,2.7 \%)$ and endocrinal (included patients with diabetic ketoacidosis) $(\mathrm{n}=7,1.46 \%)$. Miscellaneous causes include poisoning, drowning and patients with orthopaedic causes (including limb trauma). Average length of stay in the PICU was 5.86 days (range <24 hour to 120 days).136 (37.78\%) admitted patients required mechanical ventilation and $63(46.32 \%)$ of the ventilated patient were successfully recovered.

Table 3 shows the gross outcome of the admissions and table 1 and 2 relate the age-wise and system-wise outcome of the admissions respectively. Of the 481 children admitted, 360 (74.34\%) patients survived and $117(24.31 \%)$ patients died. Maximum death $(n=51,43.59 \%)$ occurred in this age group of $>28$ days -12 months, followed by the age group13-59 months( $\mathrm{n}=32$, 


\section{JMSCR Vol||06||Issue||09||Page 1071-1075||September}

$20.92 \%), 60-120$ months( $\mathrm{n}=31,26.5 \%)$, and $>120$ months $(\mathrm{n}=3,2.56 \%)$ age groups respectively. Under 5 mortality was $(\mathrm{n}=83) 64.51 \%$ (including $43.59 \%$ infant mortality and excluding neonates). Death maximally documented in patients admitted with respiratory system involvement $(n=36$,
$30.77 \%)$, thereafter with neurological system $(\mathrm{n}=26,22.22 \%)$ involvement. Mortality in patients with cardiovascular, renal system involvement and sepsis were $12.82 \%, \quad 13.68 \%$ and $12.82 \%$ respectively.

Table 1:Age distribution of children admitted in PICU

\begin{tabular}{|c|c|c|c|}
\hline Age & No of patients admitted (Percentage) & Patients Survived (Percentage) & Patients died (Percentage) \\
\hline$>28$ days-12 months & $170(35.34 \%)$ & $119(56.41 \%)$ & $51(43.59 \%)$ \\
\hline $13-59$ months & $153(31.81 \%)$ & $120(78.43 \%)$ & $32(20.92 \%)$ \\
\hline $60-120$ months & $118(24.53 \%)$ & $84(73.50 \%)$ & $31(26.5 \%)$ \\
\hline$>120$ months & $40(8.32 \%)$ & $37(97.44 \%)$ & $3(2.56 \%)$ \\
\hline Total & 481 & 360 & 117 \\
\hline
\end{tabular}

Note: 1 patient of age grioup 36-49 months and 3 patients of 60-120 months were left against medical advice

Table 2: Morbidity and mortality pattern in total admission according to system involved/causes

\begin{tabular}{|c|c|c|c|}
\hline Diagnosis & No. of patients admitted (Percentage) & Survived (Percentage) & Died (Percentage) \\
\hline Neurological & $128(26.61 \%)$ & $100(78.13 \%)$ & $26(22.22 \%)$ \\
\hline Respiratory & $112(23.28 \%)$ & $74(66.07 \%)$ & $36(30.77 \%)$ \\
\hline Cardiovascular & $46(9.56 \%)$ & $31(67.39 \%)$ & $15(12.82 \%)$ \\
\hline Renal & $59(12.27 \%)$ & $43(72.88 \%)$ & $16(13.68 \%)$ \\
\hline Gastrointestinal & $63(13.1 \%)$ & $57(90.48 \%)$ & $6(5.13 \%)$ \\
\hline Sepsis /Infection & $39(8.11 \%)$ & $24(61.54 \%)$ & $15(12.82 \%)$ \\
\hline Hematological & $14(2.91 \%)$ & $11(78.57 \%)$ & $3(2.56 \%)$ \\
\hline Endocrinal & $7(1.46 \%)$ & $7(100 \%)$ & 0 \\
\hline Miscellaneous & $13(2.7 \%)$ & $13(100 \%)$ & 0 \\
\hline Total & 481 & 360 & 117 \\
\hline
\end{tabular}

Note *: Miscellanous causes include poisoning, drowing and orthopedic complaints.

Note $* *: 4$ patients were left against medical advise.

\begin{tabular}{|l|c|c|}
\hline \multicolumn{3}{|c|}{ Table3: Outcome of patients in PICU } \\
\hline Outcome & No of cases & Percentage(\%) \\
\hline Survived & 360 & 74.84 \\
\hline Expired & 117 & 24.32 \\
\hline LAMA & 4 & 0.83 \\
\hline Total & 481 & 100 \\
\hline & & \\
\hline
\end{tabular}

\section{Discussion}

The PICU is a special unit of health care delivery service for patients who are critical with potentially recoverable diseases. PICU requires a vast use of up to date equipment and highly skilled staff and demands a tremendous amount of time and effort on behalf of the medical and nursing staff to treat and improve survival of the critically ill patients. Protocol based management, rational antibiotic policy, early referral to PICU to be implemented to have a low mortality. During 
this study period 481 children were admitted in PICU. Of them, 309 (64.24\%) were male and 172 $(35.76 \%)$ were females. Male to female ratio was 1.8:1. Male: Female was found as 2.95:1 by Khilnani et $\mathrm{al}^{(3)}$ and $1.49: 1$ by I. Blessings Abhuhimhen - Iyoha et al ${ }^{(4)}$. In another study published in Pakistan by Anwarul Haque et al (5) also found that majority $(60.9 \%)$ of patients were male. Under 5year aged children constituted $67.15 \%$ admissions $(n=323)$ in this study, including $35.34 \%$ infants $(\mathrm{n}=170) \quad$ (excluding neonates). Study conducted by I. Blessing Abhulimhen - Iyoha et al ${ }^{(4)}$ revealed that $72.4 \%$ patients were aged less than 5 years (including $50.7 \%$ constituted by infants) and by Anwarul Haque et al ${ }^{(5)}$ children under 5 year were $62.5 \%$.

Paediatric intensive care admissions vary in different studies. Three most common disease categories admitted were central nervous system $(26.61 \%)$ respiratory $(23.28 \%)$ and gastrointestinal (13.1\%) in this study. Anwarul Haque et al ${ }^{(5)}$ also documented the most common cause of admission was neurological (28\%) followed by respiratory in $24.4 \%$, and study conducted by I Das ${ }^{(6)}$ also documented neurological as the major cause of admission $(30.51 \%)$ while respiratory cause was $19.37 \%$.I. Blessing Abhulimhen - Iyoha et $\mathrm{al}^{(4)}$ reported cardiovascular disease $(41.1 \%)$ as the commonest indication for admission in their series and Khilnani et $\mathrm{al}^{(3)}$ reported respiratory as the commonest cause (19.7\%), followed by neurological $(17.9 \%)$ cause of admission.

Overall mortality in this study was $24.32 \%$. This value is higher than documented by Khilnani et al (3)

With the gross mortality rate $(6.7 \%)$. Anwarul Haque et al ${ }^{(5)}$ showed the overall mortality of their PICU of $14 \%$.

I. Blessings Abhulimhen - Iyoha et $\mathrm{al}^{(4)}$ found that mortality in their centre was as low as $2.1 \%$.

Mortality in patients depends on many factors such as demographic and clinical characteristic of population, infrastructure, non-medical factors (management and organization, time taken to reach health care), admission practice, and also affected by ICU performance ${ }^{(6)}$.

The high mortality in our study may be contributed by several factors. Important contributory factor might be that, central nervous system was responsible for $26.61 \%$ of admissions in our PICU and many of these cases were Acute Encephalitic Syndrome including viral meningo encephalitis and Japanese B Encephalitis which may not have good prognosis. Another cause of high mortality is that, lot of patients requiring PICU admissions have to be managed in the ward due to paucity of beds in PICU and thereafter shifted to PICU in the late stage of the disease process.

\section{Conclusions}

The present study highlights neurological, respiratory and gastrointestinal disorders to be the leading cause of admissions in PICU, catering to the needs of critical care of the in-patients from Pediatric Medicine and in-patients of pediatric age from other specialities and super specialties. This study is therefore conducted to audit the pattern of cases being admitted into the PICUof this tertiary care teaching hospital and their outcome.

Further well planned, systematic and large-scale studies in this field is needed by using standardized methodologies, to estimate the leading causes of admission, morbidity and mortality in the PICU with the representation from different regions of India, to provide an effective PICU care in reducing the mortality and morbidity of critically ill patients, giving the desirable outcome.

Funding: No funding sources

Conflict of Interest: None declared

Ethical approval: Approved

\section{References}

1. Wheeler, Derek S., Wong, Hector R., Shanley, Thomas P. (Eds.) Science and Practice of Pediatric Critical Care Medicine, DOI 10.1007/978-1-84800-921- 
9_2, (C) Springer-Verlag London Limited 2009

2. Gupta D, Butola K.S., Nath B, Masood J. Retrospective review of disease patterns and outcomes of patients admitted inMedical Intensive Care Unit (MICU) of Government Medical College and Hospital, Srinagar (Uttarakhand) .Journal of Preventive Medicine and Holistic Health, January-June 2016;2(1):24-27 DOI: $10.5958 / 2454-6712.2016 .00006 .7$

3. Khilnani P, Sarma D, Singh R, Uttam R, Rajdev S, Makkar A, et al. Demographic profile and outcome analysis of a tertiary level pediatric intensive care unit. Indian J Pediatr2004; 71:587-91. [PubMed]

4. Blessing I. Abhulimhen - Iyoha, Suneel Kumar Pooboni and Nanda Kishore Kumar Vuppali. Morbidity Pattern and Outcome of Patients Admitted into a Pediatric Intensive Care Unit of India. Indian Journal of Clinical Medicine 2014: $5 ; 1-5$.

5. Haque A, Bano S. Clinical profile and outcome in a paediatric intensive care unit in Pakistan. J Coll Physicians Surg Pak 2009; 19:534-5.doi: 08.2009/JCPSP.534535. [PubMed]

6. Das I, Bezboruah G, Pathak K, Rahman MClinical Profile And Outcome of Patients Admitted In Pediatric Intensive Care Unit of Gauhati Medical College \& Hospital. .e-ISSN: 2279-0853, p-ISSN: 2279- 0861.Volume 16, Issue 12 Ver. II (Dec. 2017): 27-29. DOI: 10.9790/08531612022729

7. Bertolini G, Donata RAC, Apolone G. PRISM - an assessment of its performance in a sample of 26 Italian ICU'S. Crit Care Med. 1988;26:1427-1432. 